\section{Om utställningar i Nordisk Museologis tidigare nummer}

Museibegreppet kan (som bekant?) betraktas som en sammanfattning av den museologiska processen - människans och samhällets hantering av materiella minnen i sin omvärld. Det är då oundvikligt att allt som skrivs om museer också berör, har konsekvenser, för processens sista led driften att visa, att förmedla (och påverka, övertyga?). Med andra ord särskilt för museernas utställningar. Den reflektion och diskussion som gäller målsättning, samlande, dokumentation, bevarande osv. har oundvikligen följder för utställningsverksamheten, ger dess förutsättningar och ramar. På motsvarande sätt återverkar allt som tänks, sägs och skrivs om utställningar också på processens övriga led.

Följaktligen skulle alltså kunna hävdas att allt som skrivits $i$ vår tidskrift handlat om utställningar, direkt eller indirekt. De direkt utställningsrelaterade uppsatserna i föreliggande nummer tar primärt sikte på utställningars formuttryck, 'utställningsspråken'. Detta gjorde också en rad uppsatser - med viss betoning av konstmuseernas problematik (de flesta presenterade vid Museumshøjskolens Holstebro-kurs 'Udstilling eller forestilling' 1992) - i Nordisk Museologi 1995/1:

Paludan-Müller, Carsten. Museums betydning den fraktale utfordring.

Brandt, Per Aage. Hvad er et museum? En semiotisk undersökelse.

Morell, Lars. Paladsrevolutioner.

Ågren, Per-Uno. Om museer och utställningsspråk. Persson, Eva. Producenten, konstnären och formgivaren. Reflexioner kring tre roller.
Millard, John. Art on Tyneside.

Wiktorsson, Stefan. Museiljus och teaterljus.

Løveid, Birthe Marie. Om strandvandringer og annen unyttig eksersis.

\section{Konstmuseernas utställningsproblem àterkommer i många tidigare nummer:}

Fischer, Erik. Kunstens museer - museernes kunst? 1993/1.

Groys, Boris. The Logic of the Collection. 1993/2. Grasskamp, Walter. Reviewing the Museum - or:

The Complexity of Things. 1994/1.

Sydhoff, Beate. Det musiska museet. 1995/1.

Petersen, Vibeke. Museet og kunstens iscenesættelse. 1996/2.

Sydhoff, Beate. Konstmuseet som metafor. 1996/2.

\section{Utställandets historia behandlas i flera uppsatser:}

Bencard, Mogens. Museerne og Verdensordenen. Kunstkammerets opståen og grundidé. 1993/1.

Jensen, Jørgen. C.J. Thomsens museum - en guldaldervisjon. 1993/1.

Olsen, Bjørnar. Det arkeologiske museum, momenter til en kritikk. 1993/1.

Becker, Annesofie. The Genealogy of the Museum. $1993 / 2$.

MacGregor, Arthur. Antiquarian Attitudes. 1993/2.

Rasmuseen, Holger. Hvorfor opstod Folkemuseet? $1993 / 2$.

Pomian, Krzysztof. Museums, Paintings and History. 1993/2.

Olsen, Bjørnar \& Sveistad, Asgeir. Creating Prehistory. 1994/1.

Bencard, Mogens. Kunstkammers and Museums. $1994 / 1$.

von Plessen, Marie-Louise. Order and Culture.

Passages of Popularization. 1994/1.

Wagner, Peter. Fra kunstkammer til moderne museum. 1994/2. 
NORDISK MUSEOLOGI $1997 \cdot 1$

86 Andersen, Hemming. Fysik og museum: Hauchs physiske Cabinet. 1994/2.

Rosander, Göran. Museerna och tidsandans förändring. 1996/1.

Rentzhog, Sten. 70-talets museum - 25 år efteråt. $1996 / 1$.

Wäre, Ritva. The National Museum of Finland 1916-1996. 1996/2

\section{Generella problem som behandlar} museibesökarens möte med utställningen àterfinns särskilt $i$ :

Hudson, Kenneth. The Great European Museum. $1993 / 2$.

Treinen, Heiner. Vad söker besökaren i museet? 1994/2.

Meldgaard, Inge. Fremtidens museumspædagogik. $1994 / 2$.

Björnsson, Anders. Museer, medier och minnandet. $1994 / 2$.

Maure, Marc. The exhibition as theatre. 1995/2.

Lundberg, Bengt. Museernas maktspråk. 1996/1.

Hudson Kenneth. The Wrong and the Right Road for Museums. 1996/1.

\section{Utställarens tolkningsproblem diskuteras:}

Lönnqvist, Bo. Gränsen som museal struktur. 1993/2.

Gjestrum, John Aage. Museology and Research - in a Norwegian Perspective. 1995/2.

Skougaard, Mette. Folk Museums in Conflicts of National Heritage. 1995/2.

Sandahl, Jette. Proper Objects among other Things. $1995 / 2$.

Wolff, Bente. Material Objects in a Cross-cultural Perspective. 1995/2.

Silvén-Garnert, Eva. Objects in the World and Objects in Museums. 1995/2.

Garnert, Jan. Rethinking Visual Representation. $1995 / 2$.
Vasström, Annette. Genstandsinsamling og arbejderkultur. 1996/1.

Persson, Eva. Hellre en nybadad syndare... 1996/1.

Bårtvedt, Randi. Industrisamfunn og kulturarv. 1996/1.

Åhlvik, Clara. Rätten till en alldeles egen ram. 1996/1.

Gulløv, Hans Christian. Eskimokultur, arkæologi og museumssamlinger. 1996/2.

Christie, Inger Lise. Utstillingen 'Med egin hand'. $1996 / 2$

Minkkinen, Aimo. The Lenin Museum in Tampere. 1996/2.

Här ovan har 50 av tidskriftens (t.o.m. 1996) 106 uppsatser förtecknats. Var därmed inte säker på, bäste kunskaps- och inspirationssökare, att inte $\mathrm{i}$ de övriga gömmer sig meningar som är viktiga för eftertankar om museiutställningens mångskiftande väsen! 